\title{
Erectile dysfunction is frequent in systemic sclerosis and associated with severe disease: a study of the EULAR Scleroderma Trial and Research group
}

Chingching Foocharoen ${ }^{1}$, Alan Tyndall', Eric Hachulla², Edoardo Rosato ${ }^{3}$, Yannick Allanore4, Dominique Farge-Bancel ${ }^{5}$, Paola Caramaschi ${ }^{6}$, Paolo Airó ${ }^{7}$, Starovojtova M Nikolaevna ${ }^{8}$, José António Pereira da Silva ${ }^{9}$, Bojana Stamenkovic ${ }^{10}$, Gabriela Riemekasten ${ }^{11}$, Simona Rednic ${ }^{12}$, Jean Sibilia ${ }^{13}$, Piotr Wiland ${ }^{14}$, Ingo Tarner ${ }^{15}$, Vanessa Smith ${ }^{16}$, Anna T Onken ${ }^{17}$, Walid Ahmed Abdel Atty Mohamed ${ }^{18}$, Oliver Distler ${ }^{19}$, Jadranka Morović-Vergles ${ }^{20}$, Andrea Himsel ${ }^{21}$, Paloma Garcia de la Peña Lefebvre ${ }^{22}$, Thomas Hügle ${ }^{1}$ and Ulrich A Walker ${ }^{r^{*}}$

\begin{abstract}
Introduction: Erectile dysfunction (ED) is common in men with systemic sclerosis (SSc) but the demographics, risk factors and treatment coverage for ED are not well known.

Method: This study was carried out prospectively in the multinational EULAR Scleroderma Trial and Research database by amending the electronic data-entry system with the International Index of Erectile Function-5 and items related to ED risk factors and treatment. Centres participating in this EULAR Scleroderma Trial and Research substudy were asked to recruit patients consecutively.

Results: Of the 130 men studied, only 23 (17.7\%) had a normal International Index of Erectile Function-5 score. Thirtyeight per cent of all participants had severe ED (International Index of Erectile Function-5 score $\leq 7$ ). Men with ED were significantly older than subjects without ED (54.8 years vs. 43.3 years, $P<0.001)$ and more frequently had simultaneous non-SSc-related risk factors such as alcohol consumption. In 82\% of SSc patients, the onset of ED was after the manifestation of the first non-Raynaud's symptom (median delay 4.1 years). ED was associated with severe cutaneous, muscular or renal involvement of SSc, elevated pulmonary pressures and restrictive lung disease. ED was treated in only $27.8 \%$ of men. The most common treatment was sildenafil, whose efficacy is not established in ED of SSc patients.

Conclusions: Severe ED is a common and early problem in men with SSc. Physicians should address modifiable risk factors actively. More research into the pathophysiology, longitudinal development, treatment and psychosocial impact of ED is needed.
\end{abstract}

\section{Introduction}

Systemic sclerosis (SSc) is a connective tissue disorder in which vascular alterations and endothelial damage are prominent and lead to progressive and widespread dysfunction of various organs. Vascular symptoms such as Raynaud's phenomenon, digital ulcers and pulmonary

\footnotetext{
* Correspondence: ulrich.walker@fps-basel.ch

'Department of Rheumatology, Basel University, Burgfelderstrasse 101, Basel 4012, Switzerland

Full list of author information is available at the end of the article
}

arterial hypertension are also a frequent target of diagnostic and therapeutic efforts [1]. Men with SSc may develop erectile dysfunction (ED), a vascular complication that is not frequently addressed in studies. Owing to the predominance of the female gender in SSc, studies of ED in SSc men are more difficult to perform. The available data from small studies have suggested that ED is more common in SSc than in the normal population and in other autoimmune diseases [2-4]. ED has been attributed to a vascular process with

\section{() Biomed Central}


diminished arterial blood supply of the corpus cavernosum [5-8], corporeal fibrosis and accumulation of extracellular matrix [5-7].

This study aims to confirm the high prevalence using an unprecedentedly large multicentre cohort, and to describe hitherto unaddressed SSc characteristics (autoantibody status, SSc subtype, disease duration) of men with ED, to study SSc-related complications and nonrelated comorbidities as factors in the development of ED, and to report on current treatment regimens.

\section{Materials and methods Data collection}

The study was performed using the multinational database of the EULAR Scleroderma Trial and Research (EUSTAR) group, which was inaugurated in 2004. Participating centres are required to have local ethics committee approval; patients must provide informed written consent prior to entry into the Minimal Essential Data Set [9]. Patients must fulfil the American College of Rheumatology classification criteria for SSc. For the purpose of this study, the Minimal Essential Data Set online electronic data-entry system - which prospectively follows patients on yearly visits - was amended by a separate data-entry page with items specific to the ED study. EUSTAR centres intending to participate in the ED study were displayed in this separate data-entry system and were asked to provide all men consecutively with the International Index of Erectile Function-5 (IIEF-5), a self-administered questionnaire that is validated in several languages, has high retest reliability, and has demonstrated sensitivity and specificity for detecting treatment-related changes [10]. The IIEF-5 provides a numerical score that is classified into five categories: severe ED (scores 5 to 7 ), moderate ED (scores 8 to 11 ), mild to moderate ED (scores 12 to 16), mild ED (sores 17 to 21 ), and no ED (scores 22 to 25 ).

In addition to the IIEF-5 instrument, men were asked to provide information about the time of ED onset and the use of phosphodiesterase- 5 inhibitors for the specific purpose of ED treatment (not for pulmonary hypertension), as well as intraurethral or intracavernous prostaglandin preparations. Physicians were also questioned about factors known to increase the risk for ED, such as hypercholesterolaemia, diabetes mellitus, stroke, smoking, peripheral macroangiopathy and coronary heart disease.

\section{Statistical analysis}

The dataset was analysed using Stata version 11.0 (StataCorp Inc., College Station, TX, USA). SSc presentations were analysed cross-sectionally for associations between ED and other clinical features of ED. Continuous data were presented as the mean ( \pm standard deviation) or the median with interquartile range (IQR) as appropriate, while binary parameters were presented as percentages. Odds ratios with $95 \%$ confidence intervals and linear regressions were calculated to estimate effect sizes. Variables with $P<0.1$ were then entered into a multivariate logistic regression model.

\section{Results}

\section{Participants}

Twenty-two EUSTAR centres in 13 countries participated in this study, which started in October 2009. These EUSTAR centres were prospectively following 2,469 women and 463 men (gender ratio 5.3:1). At the time of census in May 2011, the centres had recruited a total of 130 men for this study. A comparison between study participants and nonparticipants demonstrates that the participants were representative of the male population in the EUSTAR centres with respect to important demographic parameters and disease characteristics such as age, antinuclear antibodies, and disease duration (Table 1). Participants had a higher proportion of puffy hands and digital ulcers, as well as a higher modified Rodnan skin score, but less frequently an impairment of the diffusion capacity of the lung for carbon monoxide below $80 \%$ of normal. Differences in systolic pulmonary arterial pressure estimated by echocardiography were statistically significant but medically less relevant.

\section{Prevalence of erectile dysfunction in systemic sclerosis}

Of the 130 participants, only 23 men (17.7\%) had a normal IIEF-5 score $(\geq 22)$. Two men had not engaged in any sexual activity in the 6 months prior to filling out the IIEF-5 questionnaire and could therefore neither be attributed to the ED group or to the non-ED group. The remaining 105 men (81\%) had variable degrees of ED. The largest group of all participants (38\%) had severe ED (Figure 1). The median IIEF-5 score of all SSc patients was 13 (IQR 6 to 19). Among the men with ED, the median IIEF-5 score was 11 (IQR 5 to 16).

\section{Comorbidities}

A number of conditions are associated with ED in the general population. These conditions include cardiovascular risk factors, medications (antidepressants, sedatives, neuroleptics, antiepileptics, diuretics), alcoholism, neurological and endocrine disorders, as well as prostatic disease $[8,11,12]$. The majority of the participating men had at least one such comorbidity (Table 2). Men with ED more frequently had more than one simultaneous comorbidity than men with normal erections.

Traditional cardiovascular risk factors such as arterial hypertension, diabetes mellitus, coronary heart disease, hypercholesterolaemia and smoking were not more 
Table 1 Characteristics of men that were included in the ED substudy by the 22 participating centres compared to those not included.

\begin{tabular}{|c|c|c|c|}
\hline & Nonparticipants $(n=463)$ & Participants $(n=130)$ & $P$ value \\
\hline Age (years) & $54.3(46.0$ to 64.1$)$ & $52.3(45.1$ to 61.5$)$ & 0.12 \\
\hline SSc duration by Raynaud's phenomenon (years) & $6.4(3.4$ to 11.7$)$ & 7.0 (3.7 to 11.9$)$ & 0.21 \\
\hline SSC duration by first non-Raynaud's symptom (years) & $5.4(2.7$ to 9.2$)$ & $6.0(3.0$ to 10.3$)$ & 0.20 \\
\hline Topoisomerase I (Scl70)-autoantibodiespositive & 42.8 & 46.7 & 0.44 \\
\hline Anti-centromere autoantibodies-positive & 14.9 & 15.7 & 0.82 \\
\hline U1RNP-positive & 6.5 & 4.7 & 0.51 \\
\hline RNA polymerase III-positive & 9.4 & 2.8 & 0.08 \\
\hline Diffuse SSC & 56.8 & 63.7 & 0.18 \\
\hline Puffy hands & 34.3 & 54.6 & $<0.001^{*}$ \\
\hline mRSS & $10(4$ to 16$)$ & $13(6$ to 20$)$ & $0.01^{*}$ \\
\hline$m R S S>20$ & 16.8 & 25.0 & 0.05 \\
\hline C-reactive protein elevation & 33.6 & 24.5 & 0.07 \\
\hline Digital ulcers & 34.7 & 44.0 & $0.04^{*}$ \\
\hline Synovitis & 13.1 & 20.0 & 0.05 \\
\hline Joint contractures & 33.0 & 31.8 & 0.81 \\
\hline Tendon friction rubs & 10.2 & 10.0 & 0.94 \\
\hline Muscle weakness & 22.2 & 20.9 & 0.76 \\
\hline Muscle atrophy & 11.1 & 15.5 & 0.17 \\
\hline Creatine kinase elevation & 11.6 & 13.3 & 0.58 \\
\hline Oesophageal symptoms & 54.4 & 60.4 & 0.23 \\
\hline Stomach symptoms & 16.0 & 13.5 & 0.50 \\
\hline Intestinal symptoms & 18.8 & 12.6 & 0.11 \\
\hline Lung fibrosis on chest $\mathrm{X}$-ray or HRCT & 60.4 & 56.7 & 0.59 \\
\hline Forced vital capacity (\% predicted) & 89 (75 to 101$)$ & $92(81$ to 103$)$ & 0.36 \\
\hline Forced vital capacity $<80 \%$ & 32.2 & 23.3 & 0.10 \\
\hline DLCO (\% predicted) & 66 (49 to 82$)$ & 69 (55 to 88$)$ & 0.05 \\
\hline DLCO $<80 \%$ & 71. & 59.1 & $0.01^{*}$ \\
\hline PAPsys (mmHg) & 30 (25 to 37$)$ & 27 (20 to 36$)$ & $0.004^{*}$ \\
\hline PAPsys > 40 mmHg & 22.3 & 19.4 & 0.51 \\
\hline Diastolic dysfunction & 20.4 & 18.8 & 0.70 \\
\hline Pericardial effusion & 7.1 & 5.7 & 0.64 \\
\hline Left ventricular ejection fraction $<60 \%$ & 25.1 & 20.0 & 0.31 \\
\hline Arterial hypertension & 21.5 & 23.6 & 0.75 \\
\hline Renal crisis & 3.3 & 4.5 & 0.50 \\
\hline Proteinuria & 8.6 & 9.4 & 0.79 \\
\hline EULAR SSc activity score & 1.5 (0.5 to 3.0$)$ & $2(0.5$ to 3.5$)$ & 0.27 \\
\hline High SSc activity (score $\geq 3$ ) & 27.2 & 35.2 & 0.19 \\
\hline Hypocomplementaemia & 5.0 & 5.9 & 0.71 \\
\hline
\end{tabular}

Demographic parameters and disease characteristics from the EULAR Scleroderma Trial and Research database

Data presented as median (interquartile range) or percentage. DLCO; diffusion capacity of the lung for carbon monoxide; HRCT, high resolution computed tomography; mRSS; modified Rodnan skin score; PAPsys; systolic pulmonary arterial pressure; SSc, systemic sclerosis. ${ }^{*}$ Significant at $P<0.05$.

prevalent in men with ED. Significantly more men with ED (13.8\%) than those without ED (0\%) consumed alcohol in excess of 2 units per day and twice as many had depression (not significant). Men with severe ED (IIEF-5 scores 5 to 7 ) had a low prevalence of alcoholism (5.7\%), but the highest prevalence of depression as judged by the treating physician (10.8\%). Central nervous system dysfunction was reported only in men with ED, in which it consisted of stroke, multiple sclerosis and dementia. More men with ED than those without ED had prostatic disease, whereas endocrine or medication-related factors did not differ between both groups.

\section{Demographics, disease characteristics and predictors of} ED

Patients with ED were significantly older than subjects without ED (Table 3). The median SSc duration was similar in both groups (approximately 7 years if 


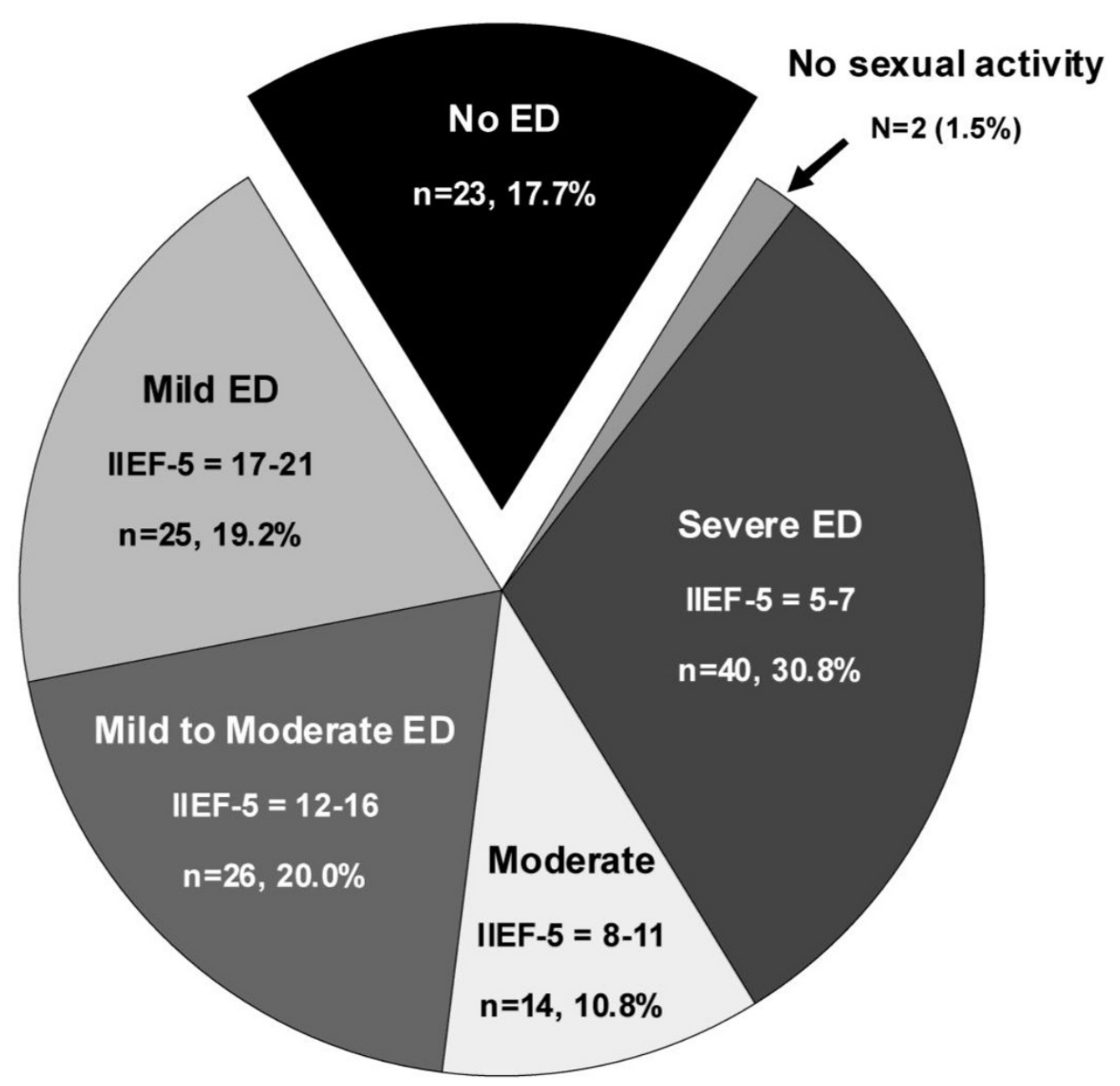

Figure 1 Prevalence and severity of erectile dysfunction among the 130 participants. ED, erectile dysfunction; IIEF-5, International Index of Erectile Function-5.

measured from the onset of Raynaud's phenomenon, and 6 years if determined from the first non-Raynaud's symptom). The median duration of ED was 1.8 years (IQR 0.3 to 4.9 ). Patients with more severe ED had experienced erectile problems for a longer time (median of 4 years in patients with IIEF- 5 score $\leq 7$ ) than those with less severe ED. In the majority of patients, the erectile problem started after the onset of SSc (in 90.1\% of SSc patients after the onset of Raynaud's phenomenon, and in $82.1 \%$ of men after the manifestation of the first non-Raynaud's symptom of SSc). The median time interval from the onset of the first non-Raynaud's symptom of SSc to the onset of ED was 4.1 years (IQR 1.5 to 8.3 years). An analysis by ED duration revealed a negative correlation between IIEF-5 score and time of ED $(P=0.03)$. The IIEF-5 score was not correlated with SSc duration, as measured either from the onset of Raynaud's phenomenon or from the onset of first non-
Raynaud's symptom, however, and about one-fifth of all men have maintained normal erections many years after SSc onset (Figure 2).

A total $52.4 \%$ of men without ED had one of the antinuclear antibodies typically tested for SSc; for example, antibodies directed against topoisomerase I (Scl70), centromere, U1 RNP and RNA polymerase III. Among men with ED these typical antinuclear antibodies were more prevalent (69.2\%) than in men without ED (52.4\%), but the difference was not statistically significant. The prevalence of autoantibodies against topoisomerase I (Scl70) was similar in the ED group and the non-ED group, but antibodies directed against centromere, U1RNP and RNA polymerase III were more frequent with ED (Table 3).

The presence of ED was also associated with more severe organ involvement in SSc. Men with any form of ED had a higher modified Rodnan skin score, and more 
Table 2 Comorbidities of the participants

\begin{tabular}{|c|c|c|c|}
\hline & $\begin{array}{l}\text { No erectile dysfunction }(n= \\
\text { 23) }\end{array}$ & $\begin{array}{l}\text { Erectile dysfunction }(n= \\
105)\end{array}$ & $\begin{array}{l}\text { Odds ratio ( } 95 \% \text { confidence } \\
\text { interval) }\end{array}$ \\
\hline \multicolumn{4}{|l|}{ Cardiovascular risk factors } \\
\hline Systemic arterial hypertension & 14.3 & 24.1 & $1.11(0.92$ to 1.34$)$ \\
\hline Diabetes mellitus & 4.4 & 6.9 & 1.08 (0.82 to 1.42$)$ \\
\hline Coronary heart disease & 4.4 & 13.3 & 1.17 (0.98 to 1.39$)$ \\
\hline Hypercholesterolaemia & 19.1 & 13.3 & $0.92(0.70$ to 1.21$)$ \\
\hline History of smoking & 31.8 & 42.6 & 1.09 (0.92 to 1.29$)$ \\
\hline Cigarette smoking (pack-years) & 15 (10 to 21$)$ & 20 (9 to 30$)$ & $P=0.69$ \\
\hline \multicolumn{4}{|l|}{ Medication } \\
\hline $\begin{array}{l}\text { Antidepressant, sedative, neuroleptic or } \\
\text { antiepileptic }\end{array}$ & 4.4 & 9.1 & $1.12(0.89$ to 1.40$)$ \\
\hline Thiazides or spironolactone & 4.4 & 7.0 & $1.08(0.82$ to 1.43$)$ \\
\hline Alcohol consumption (> 2 units/day) & 0 & 13.7 & $1.27(1.15 \text { to } 1.40)^{*}$ \\
\hline \multicolumn{4}{|l|}{ Other } \\
\hline Depression & 4.6 & 9.0 & 1.11 (0.88 to 1.39$)$ \\
\hline Central nervous system problems & 0 & 3.9 & $1.23(1.13 \text { to } 1.35)^{*}$ \\
\hline Prostatic disease & 0 & 8.4 & $1.24(1.13 \text { to } 1.36)^{*}$ \\
\hline $\begin{array}{l}\text { Hormonal (hypogonadism, } \\
\text { hyperprolactinaemia) }\end{array}$ & 0 & 2.8 & $1.23(1.11$ to 1.36$)$ \\
\hline \multicolumn{4}{|l|}{ Number of comorbidities per patient } \\
\hline At least one comorbidity & 52.2 & 61.5 & 1.07 (0.90 to 1.28$)$ \\
\hline At least two comorbidities & 13.0 & 36.5 & $1.21(1.05 \text { to } 1.40)^{*}$ \\
\hline At least three comorbidities & 4.4 & 14.4 & $1.17(1.00 \text { to } 1.34)^{*}$ \\
\hline At least four comorbidities & 0 & 5.8 & $1.23(1.13 \text { to } 1.35)^{*}$ \\
\hline At least five comorbidities & 0 & 1 & $1.22(1.13 \text { to } 1.33)^{*}$ \\
\hline
\end{tabular}

Data presented as median (interquartile range) or percentage. The star $\left(^{*}\right)$ denotes statistical significance.

frequently had muscle atrophy, a history of renal crisis, elevated pulmonary arterial pressure and restrictive lung disease (Table 3). Men with ED also had higher EULAR SSc activity scores than men with normal erectile function [13]. On multivariate analysis, however, only age remained a predictor of $\mathrm{ED}\left(P=0.02, R^{2}=0.42\right)$.

We also performed an analysis of organ involvement by ED severity (Table 4$)$. In this analysis, older age $(P<$ $0.001)$ and impaired pulmonary function $(P=0.006$ for normal forced vital capacity, $P=0.01$ for forced vital capacity $<80 \%$ of normal) were associated with ED severity - indicators of pulmonary hypertension and SSc activity.

\section{Treatment of erectile dysfunction}

Treatment information was obtained in 101 of the 105 men with ED (Table 5). A total $72.2 \%$ of men with abnormal erections did not receive any treatment for ED. In the remaining $27.8 \%$ of men, ED was treated with a phosphodiesterase- 5 inhibitor as the recommended first-line modality in the non-SSc population. Sildenafil was the agent most commonly used; seven of the 15 men using sildenafil also had concomitant pulmonary arterial hypertension. Tadalafil was used in a total of 11 men. The proportion of patients with tadalafil and concomitant pulmonary arterial hypertension was not captured because the study was launched prior to the approval of tadalafil for pulmonary arterial hypertension. Two men with moderate ED were treated with intracavernous alprostadil injections. Three of 101 men with ED (IIEF-5 scores of 10, 16 and 20) received combination therapy. One man was treated with sildenafil plus vardenafil, one man received sildenafil plus tadalafil and one man received sildenafil plus intracavernous alprostadil.

Other second-line treatments for ED, such as intraurethral alprostadil applications or vacuum devices, were not used. Two patients had received a penile prosthesis for severe ED; one patient had a normal IIEF-5 score after this procedure. The ED in the second patient who also suffered from multiple sclerosis had not improved from the otherwise uneventful prosthesis implantation.

\section{Discussion}

Connective tissue diseases more frequently affect women and most studies have not addressed medical problems specific to men. This study represents the largest investigation so far of ED in men with SSc. The prevalence of ED in our survey is similar to, or even exceeds, the estimates from smaller studies $[3,4]$ and is 
Table 3 Comparison of participants with and without ED

\begin{tabular}{|c|c|c|c|}
\hline & $\begin{array}{l}\text { No erectile dysfunction }(n= \\
\text { 23) }\end{array}$ & $\begin{array}{l}\text { Erectile dysfunction }(n= \\
105)\end{array}$ & $\begin{array}{l}\text { Odds ratio ( } 95 \% \text { confidence } \\
\text { interval) }\end{array}$ \\
\hline IIEF-5 score & $23(22$ to 25$)$ & $11(5$ to 16$)$ & $P<0.001^{*}$ \\
\hline Age $(\text { years) })^{a}$ & 45 (35.1 to 51.8$)$ & 55.7 (47.1 to 62.9) & $P<0.001^{*}$ \\
\hline SSC duration by Raynaud's phenomenon (years) & $7.2(4.3$ to 15.3$)$ & 7.0 (3.4 to 11.6$)$ & $P=0.44$ \\
\hline $\begin{array}{l}\text { SSc duration by first non-Raynaud's symptom } \\
\text { (years) }\end{array}$ & $6.6(4.3$ to 11.8$)$ & 5.6 (2.8 to 9.8$)$ & $P=0.41$ \\
\hline Topoisomerase I (Scl70)-positive & 47.6 & 45.1 & 0.98 (0.80 to 1.19$)$ \\
\hline ACA-positive & 5.0 & 18.8 & $1.21(1.02 \text { to } 1.44)^{*}$ \\
\hline U1RNP-positive & 0 & 5.9 & $1.25(1.12 \text { to } 1.39)^{*}$ \\
\hline RNA polymerase III-positive & 0 & 3.5 & $1.20(1.08 \text { to } 1.33)^{*}$ \\
\hline Diffuse SSC & 50 & 65.9 & $1.13(0.92$ to 1.40$)$ \\
\hline Puffy hands & 57.1 & 52.9 & 0.97 (0.80 to 1.16$)$ \\
\hline mRSS & 7 (2 to 19$)$ & 14 (8 to 23$)$ & $P=0.05^{*}$ \\
\hline mRSS $>20$ & 15.8 & 26.8 & $1.13(0.91$ to 1.40$)$ \\
\hline C-reactive protein elevation & 14.3 & 25.3 & $1.13(0.93$ to 1.37$)$ \\
\hline Raynaud's phenomenon & 90.5 & 95.5 & 1.22 (0.69 to 2.17$)$ \\
\hline Digital ulcers & 47.6 & 41.9 & 0.95 (0.79 to 1.16$)$ \\
\hline Synovitis & 19.1 & 19.5 & $1.01(0.80$ to 1.27$)$ \\
\hline Joint contractures & 19.1 & 33.3 & 1.14 (0.95 to 1.36$)$ \\
\hline Tendon friction rubs & 4.8 & 10.3 & 1.13 (0.90 to 1.42$)$ \\
\hline Muscle weakness & 9.5 & 20.7 & 1.15 (0.96 to 1.38$)$ \\
\hline Muscle atrophy & 4.8 & 18.4 & $1.21(1.03 \text { to } 1.42)^{*}$ \\
\hline Creatine kinase elevation & 19.1 & 12.2 & $0.88(0.62$ to 1.25$)$ \\
\hline Oesophageal symptoms & 57.1 & 59.1 & $1.02(0.84$ to 1.23$)$ \\
\hline Stomach symptoms & 19.1 & 12.5 & $0.90(0.65$ to 1.23$)$ \\
\hline Intestinal symptoms & 4.8 & 15.9 & $1.19(0.99$ to 1.41$)$ \\
\hline Lung fibrosis on chest $X$-ray or HRCT & 42.9 & 56.9 & $1.13(0.87$ to 1.47$)$ \\
\hline Forced vital capacity (\% predicted) & 95 (87 to 107$)$ & 91 (78 to 192) & $P=0.52$ \\
\hline Forced vital capacity $<80 \%$ & 9.5 & 25.7 & $1.26(1.01 \text { to } 1.56)^{*}$ \\
\hline DLCO (\% predicted) & 81 (73 to 91) & 66 (53 to 82$)$ & $P=0.08$ \\
\hline DLCO $<80 \%$ & 42.9 & 63.6 & $1.24(0.95$ to 1.61$)$ \\
\hline PAPsys (mmHg) & 23.5 (0 to 28$)$ & 29 (22 to 37$)$ & $P=0.04^{*}$ \\
\hline PAPsys $>40 \mathrm{mmHg}$ & 0 & 24.4 & $1.32(1.17 \text { to } 1.50)^{*}$ \\
\hline Diastolic dysfunction & 15.8 & 17.3 & $1.02(0.79$ to 1.33$)$ \\
\hline Pericardial effusion & 5.6 & 4.4 & $0.95(0.53$ to 1.68$)$ \\
\hline Left ventricular ejection fraction $<60 \%$ & 27.8 & 18.3 & $0.88(0.65$ to 1.20$)$ \\
\hline Renal crisis & 0 & 4.6 & $1.25(1.14 \text { to } 1.38)^{*}$ \\
\hline Proteinuria & 19.1 & 6.0 & 0.68 (0.37 to 1.22$)$ \\
\hline EULAR SSC activity score & 1.0 (0.5 to 2.0$)$ & 2.5 (1.0 to 3.5$)$ & $P=0.02^{*}$ \\
\hline High SSc activity (score $\geq 3$ ) & 11.8 & 43.4 & $1.38(1.09 \text { to } 1.75)^{*}$ \\
\hline Hypocomplementaemia & 5.0 & 6.3 & 1.05 (0.72 to 1.52$)$ \\
\hline
\end{tabular}

Data presented as median (interquartile range) or percentage unless indicated otherwise. DLCO, diffusion capacity of the lung for carbon monoxide; HRCT; IIEF-5, International Index of Erectile Function-5; mRSS; modified Rodnan skin score; PAPsys, systolic pulmonary arterial pressure; $\mathrm{SSc}$, systemic sclerosis. ${ }^{\mathrm{a}} \mathrm{Age}$ presented as mean + standard deviation (minimum to maximum). The star $(*)$ denotes statistical significance

considerably higher than in the general population. A study in Massachusetts, for example, calculated the prevalence of complete impotence as 5 to $15 \%$ in men between 40 and 70 years of age in the general population [14]. The prevalence of ED in our study also exceeds estimates in other chronic disease populations, such as in diabetes mellitus (37 to $75 \%$ ) [15,16], stroke
(48\%) [17], and arterial hypertension (23 to 46\%) [18-20]. For rheumatoid arthritis the reported prevalence was $48 \%$ [4].

Patients with SSc not only have an elevated prevalence of ED, they also have more severe ED compared with the general population. The average IIEF-5 score in our study was 13.3 , which is similar to the only other study 

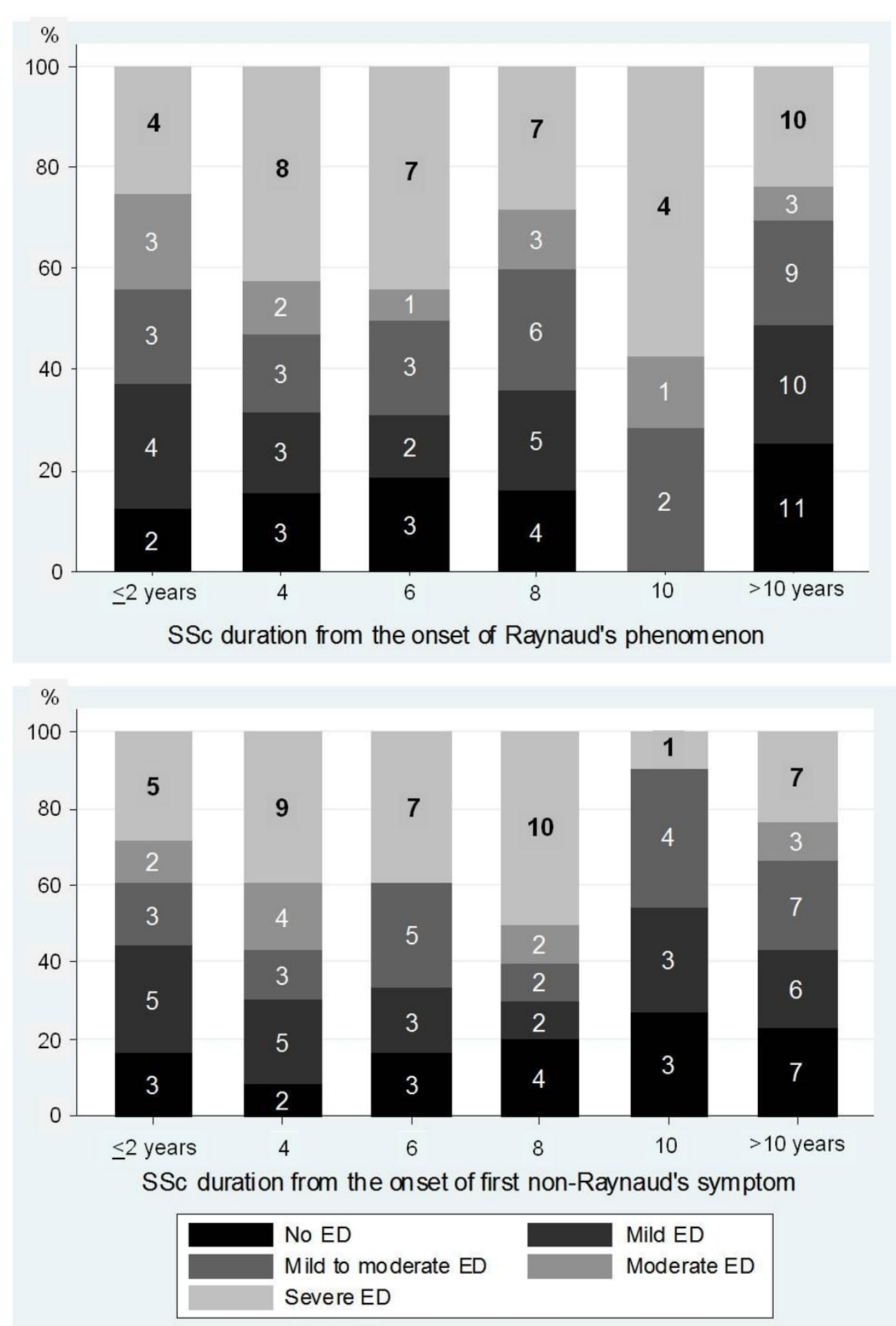

Figure 2 Severity of erectile dysfunction as a function of disease duration. Figures in bars represent the number of men within each subgroup; $y$ axis, cumulative percentages. ED, erectile dysfunction; SSC, systemic sclerosis.

in which ED severity was investigated in 17 men with SSc [6]. In comparison, the average IIEF-5 score in a non-SSc population with a similar age was 21.3 [11]. About one-third of men with SSc had severe ED in our investigation, whereas in the general population only $8.5 \%$ of the men with ED reported moderate or severe ED [11]. In men with non-SSc causes of ED - for example, diabetes $[15,16]$, arterial hypertension [18-20], and 
Table 4 Organ involvement by severity of erectile dysfunction

\begin{tabular}{|c|c|c|c|c|c|}
\hline & \multicolumn{4}{|c|}{ Erectile dysfunction severity } & \multirow[b]{2}{*}{$P$ value } \\
\hline & Mild $(n=25)$ & Mild to moderate $(n=26)$ & Moderate $(n=14)$ & Severe $(n=40)$ & \\
\hline IIEF-5 score & 19 (18 to 20$)$ & $14(13$ to 16$)$ & $10(8$ to 11$)$ & $5(5$ to 6$)$ & $<0.001^{*}$ \\
\hline Age (years) & 50.5 (45.3 to 61.0$)$ & 54.1 (47.1 to 63.9) & $54.9(48.6$ to 62.0$)$ & 57.3 (48.8 to 64.0 ) & $<0.001^{*}$ \\
\hline Duration of erectile dysfunction (years) & $1.0(0.6$ to 2.3$)$ & $1.2(0.1$ to 2.6$)$ & $2.8(0.1$ to 5.0$)$ & $4.0(1.0$ to 6.4$)$ & 0.08 \\
\hline Diffuse SSC & 59.1 & 47.6 & 72.7 & 82.1 & 0.08 \\
\hline C-reactive protein elevation & 9.1 & 18.2 & 41.7 & 37.4 & 0.06 \\
\hline Forced vital capacity (\% predicted) & 99 (86 to 108) & 100 (91 to 108$)$ & 84 (78 to 90$)$ & 81 (66 to 98$)$ & $0.006^{*}$ \\
\hline Forced vital capacity $<80 \%$ & 16.7 & 6.3 & 33.3 & 47.6 & $0.01^{*}$ \\
\hline DLCO (\% predicted) & $70(53$ to 81$)$ & 79 (61 to 90$)$ & 64 (49 to 69) & 56 (45 to 74.5$)$ & $0.02^{*}$ \\
\hline PAPsys (mmHg) & 32 (25 to 38$)$ & 25 (21 to 29$)$ & 27 (19 to 36$)$ & 35 (25 to 39$)$ & $0.006^{*}$ \\
\hline PAPsys $>40 \mathrm{mmHg}$ & 25 & 10.0 & 16.7 & 38.5 & $0.02^{*}$ \\
\hline EULAR SSC activity score & 1.5 (0.5 to 3.0$)$ & 2.5 (1.0 to 4.5$)$ & 3.5 (3.0 to 5.5$)$ & $2(0.5$ to 3.5$)$ & $0.047^{*}$ \\
\hline High SSc activity (score $>3$ ) & 26.7 & 47.1 & 83.3 & 40.0 & $0.02^{*}$ \\
\hline
\end{tabular}

Data presented as median (interquartile range) or percentage. DLCO, diffusion capacity of the lung for carbon monoxide; IIEF-5, International Index of Erectile Function-5; PAPsys, systolic pulmonary arterial pressure; SSc, systemic sclerosis. * Significant at $P<0.05$.

stroke [17] - the severity of ED was also milder than in SSc.

Although ED manifests after SSc onset in the vast majority of men [4], it appears as a relatively early symptom of SSc with a mean delay from SSc diagnosis of 2.7 years [4]. ED will probably not become a diagnostic predictor of SSc, given the fact that ED mostly follows SSc onset. This contrasts with the role of ED in the general population, in which ED is an important harbinger of subsequent cardiovascular disease $[8,21]$.

Our study confirms age as an important but nonmodifiable risk factor for ED development in SSc [6]. More importantly, our findings show an association with SSc severity in terms of restrictive lung disease and renal and pulmonary vasculopathy. Our study also examined for the first time the relationship between ED and autoantibody status, but failed to identify a protective antibody or an antinuclear antibody conferring an elevated risk of ED development. Among the modifiable risk factors of ED, the elevated alcohol consumption of men with ED deserves attention. The present data, however, do not permit one to differentiate whether alcohol consumption is a cause of ED, is a coping strategy for ED, or is unrelated to ED. Although the ED was more frequent in SSc men than in the normal population and age was an important risk factor for ED, the interpretation of the SSc effect in our study would be facilitated by the recruitment of a non-SSc control group matched for known ED risk factors.

Treatment guidelines for ED in the general population suggest that modifiable risk factors such as lifestyle, psychological or drug-related factors be minimised prior to or in conjunction with specific ED therapy $[12,22]$. In our study, about one-fifth of SSc patients had at least one such modifiable comorbidity. A higher proportion of men with SSc-related ED than those without ED had more than two comorbidities, indicating that these factors may contribute to the development of ED not only in the general population but also in patients with SSc and that these factors should be aggressively addressed. In the non-SSc population, pharmacotherapy with phosphodiesterase- 5 inhibitors is recommended as first-line specific treatment [22]. In SSc, the efficacy data of phosphodiesterase-5 inhibitors for ED with on-demand sildenafil were disappointing [23], whereas the longer-acting tadalafil is slightly better evaluated $[24,25]$. Second-line

Table 5 Treatment of erectile dysfunction

\begin{tabular}{llllll}
\hline & \multicolumn{2}{l}{ Erectile dysfunction severity } & \\
\cline { 2 - 6 } & Mild $(\boldsymbol{n}=\mathbf{2 5})$ & Mild to moderate $(\boldsymbol{n}=\mathbf{2 6})$ & Moderate $(\boldsymbol{n}=\mathbf{1 4})$ & Severe $(\boldsymbol{n}=\mathbf{4 0})$ & All $(\boldsymbol{n}=\mathbf{1 0 5})$ \\
\hline Sildenafil & 20 & 8 & 31 & 11 & 15 \\
Tadalafil & 12 & 8 & 15 & 11 & 11 \\
Vardenafil & 0 & 4 & 0 & 0 & 1 \\
Alprostadil urethral & 0 & 0 & 0 & 0 & 0 \\
Alprostadil cavernous & 0 & 0 & 15 & 0 & 2 \\
Vacuum device & 0 & 0 & 0 & 0 & 0 \\
Penile prosthesis & 0 & 0 & 0 & 5 & 2 \\
\hline
\end{tabular}

Data represent percent of men on each treatment modality. A total of 3 men received combination therapy. 
and third-line treatment options such as vacuum devices or intracavernous or intraurethral applications of alprostadil were used by only a minority of men with SSc, and a similar minority was equipped with a penile prosthesis although successful implantations were previously reported [7].

Our study has both strengths and limitations. It represents the largest analysis of impotence in men with SSc. The multicentric nature of our investigations may, on the one hand, be more representative of all men affected by the disease than a monocentric study, but on the other hand may lead to difficulties in standardising data collection. Although centres were asked to recruit men consecutively, there is always a risk of recruitment bias, as indicated by the slight differences observed between participants and non-participants. Depression was only judged by the treating physician and not captured with a validated questionnaire. Lastly, it would have been interesting to correlate the prevalence of ED with changes on nailfold capillaroscopy but these data were not available in the majority of patients.

\section{Conclusion}

Our study indicates that ED is a common, severe and early problem in men with SSc. ED is associated with a higher age of patients and the presence of restrictive lung disease, as well as with renal and pulmonary vasculopathy. The reasons for the overall low treatment coverage were not the assessed in this study but clearly a heightened awareness among physicians and more research into pathophysiology, longitudinal development, treatment and psychosocial impact are urgently needed.

\section{Abbreviations}

ED: erectile dysfunction; IIEF-5: International Index of Erectile Function-5; IQR: interquartile range; EUSTAR: EULAR Scleroderma Trial and Research; SSC: systemic sclerosis.

\footnotetext{
Acknowledgements

The authors thank the following: Becvar R, Charles University, Praha, Czech Republic; Sulli A, University of Genova, Italy; Cuomo G, Second University of Naples, Italy; Bournia VK, National University of Athens, Greece; Codullo V, University of Pavia, Italy; Novak S, Internal Medicine KBC Rijeka, Croatia; Varju C, University of Pécs, Akác u.l., Hungary; Kucharz EJ, Medical University of Silesia, Katowice, Poland; Cozzi F, University of Padova, Italy; Gabrielli B, Istituto di Clinica Medica Generale, Ancona, Italy; Martinovic D, Clinical Hospital of Split, Croatia; Braun-Moscovici Y, Rambam Medical Center, Haifa, Israel; La Corte R, University of Ferrara, Italy; Hunzelmann N, Universitätshautklinik Köln, Germany; Denton CP, Royal Free and University College London Medical School, London, UK; Kötter I, University Hospital, Tübingen, Germany; Ortiz Santamaria V, Granollers Hospital, Barcelona, Spain; Seidel M, Medizinische Klinik und Poliklinik I, Bonn, Germany; Belloli L, Humanitas Clinical Institute, Rozzano (Milano), Italy; Negrini S, Università San Martino, Genova, Italy; Strauss G, University Hospital of Gentofte, Hellerup, Denmark; Paloma Garcia de la Peña Lefebvre, Hospital Ramon Y Cajal, Madrid, Spain; Midtvedt $\varnothing$, Rikshospitalet, Oslo, Norway; Vasile M, Università di Roma La Sapienza, Rome, Italy; Opris D, Carol Davila University of Medicine \& Pharmacy, Bucharest, Romania; Herrgott I, University of Münster,
}

Germany; Derk CT, Thomas Jefferson University, Philadelphia, PA, USA; Distler J, University of Erlangen, Erlangen, Germany; Mouthon L, Hôpital Cochin, Paris, France; Susanne Ullman, University of Copenhagen, Denmark; Bohn J, Rheuma Clinic, Porto Alegre, Brazil; Pozzi MR, DH Reumatologia e Malattie Autoimmuni, Ospedale san Gerardo, Monza, Italy; Leuchten N, University Medical Center Carl Gustav Carus, Dresden, Germany; De Langhe E, Catholic University Leuven, Belgium; Yavuz S, University of Marmara, AltunizadeIstanbul, Turkey; Granel B, North Hospital, Marseille, France; de Souza Müller C, Universidade Federal do Paraná, Curitiba-Paraná, Brazil; Jimenez SA, Scleroderma Center - Thomas Jefferson University, Philadelphia, PA, USA; Zenone T, Unit of Internal Medicine, Valence, France; Pileckyte M, Hospital of Lithuanian University of Health Sciences Kauno Klinikos, Kaunas, Lithuania; Stebbings S, Dunedin School of Medicine, Dunedin, New Zealand; Vacca A, University of Cagliari, Monserrato (CA), Italy; Sampaio-Barros PD, University of São Paulo, Brazil; Stamp L, University of Otago, Christchurch, New Zealand; Then J, Universitario Jose Ma Cabral y Baez, Dominican Republic; Yargucu F, Ege University, Izmir, Turkey; Tanaseanu C, Clinical Emergency Hospital, Bucharest, Romania; Benenati A, Medica 'L.Condorelli' Università di Catania, Italy; Ancuta CM, 'GR.T. Popa' University of Medicine and Pharmacy, lasi, Romania; Adler S, University of Bern, Switzerland; Kayser C, Universidade Federal de São Paulo, Brazil; Imbert B, Centre Hospitalier Universitaire de Grenoble, France; Litinsky I, Tel Aviv Sourasky Medical Center, Tel Aviv, Israel; Guiducci S, University of Florence, Italy; Carreira P, Hospital Universitario, Madrid, Spain; Otsa K, East-Tallinn Central Hospital, Tallinn, Estonia.

\section{Author details}

'Department of Rheumatology, Basel University, Burgfelderstrasse 101, Basel 4012, Switzerland. 'Department of Internal Medicine, Hôpital Claude Huriez, Place de Verdun, Lille 59035, France. ${ }^{3}$ Centro per la Sclerosi Sistemica Dipartimento di Medicina, Università 'La Sapienza', Viale del Policlinico 155, Rome 00185, Italy. ${ }^{4}$ Rhumatologie A, Hôpital Cochin, Université Paris Descartes, Saint-Vincent-De-Paul La Roche-Guyon 27, rue du Fg SaintJacques, Paris 75679 , France. ${ }^{5}$ Department of Internal Medicine, Hospital Saint Louis, 1 avenue Claude Vellefaux, Paris 75010, France. ${ }^{6}$ Rheumatology Unit, University of Verona, Piazzale LA Scuro 10, Verona 37134, Italy. ${ }^{7}$ Rheumatology and Clinical Immunology Service, Spedali Civili di Brescia, P. le Spedali Civili 1, Brescia 25123, Italy. ${ }^{8}$ Institute of Rheumatology, Russian Academy of Medical Science, Kashirskoye Shosse, 34 A, Moscow 115522, Russia. ${ }^{9}$ Hospitais da Universidade, Coimbra 3000-075, Portugal. ${ }^{10}$ Institute for Prevention, Treatment and Rehabilitation of Rheumatic Disease, Srpskih Junaka 2, Niska Banja 18205, Serbia and Montenegro. ${ }^{11}$ Department of Rheumatology, Charité University Hospital, Schumannstraße 20/21, Berlin 10117, Germany. ${ }^{12}$ Rheumatology Clinic, University of Medicine \& Pharmacy 'Luliu Hatieganu' Cluj, Str. Clinicilor nr. 2-4, Cluj-Napoca 400006, Romania. ${ }^{13}$ Department of Rheumatology, University Hospital of Strasbourg, 1 avenue Molière 83049, Strasbourg 67098, France. ${ }^{14}$ Department of Rheumatology and Internal Diseases, Wroclaw University of Medicine, UI. Borowska 213, Wroclaw 50-556, Poland. ${ }^{15}$ Department of Rheumatology and Clinical Immunology, Justus-Liebig-University, Benekestraße 2-8, Bad Nauheim 61231, Germany. ${ }^{16}$ Department of Rheumatology, University of Ghent, De Pintelaan 185, Ghent 9000, Belgium. ${ }^{17}$ Department of Dermatology and Allergy, TU Munich, Biedersteiner Straße 29, Munich 80802, Germany. ${ }^{18}$ Unit of Rheumatology, Alexandria University Student Hospital, Champlion Square Mazarita, Alexandria, Egypt. ${ }^{19}$ Department of Rheumatology, University Hospital Zurich, Gloriastrasse 25, Zurich 8032, Switzerland. ${ }^{20}$ Division of Clinical Immunology and Rheumatology, University Hospital Dubrava, Av. G. Šuška 5, Zagreb 10000, Croatia. ${ }^{21}$ Department of Rheumatology, Johann Wolfgang Goethe University, Theodor-Stern-Kai 7, Frankfurt am Main 60590, Germany. ${ }^{22}$ Hospital Madrid Norte, c/OÑA № 10, Madrid 28050, Spain.

\section{Authors' contributions}

UAW participated in the design of the study and statistical analysis and prepared the manuscript. CF performed the statistical analysis and helped to draft the manuscript. AT and TH participated in the design of the study and helped to draft the manuscript. All other coauthors participated in the data acquisition and helped to draft the manuscript. All authors read and approved the final manuscript.

\section{Competing interests}

The authors declare that they have no competing interests. 
Received: 18 September 2011 Revised: 11 December 2011

Accepted: 20 February 2012 Published: 20 February 2012

\section{References}

1. Herrick A: Diagnosis and management of scleroderma peripheral vascular disease. Rheum Dis Clin North Am 2008, 34:89-114.

2. Lally EV, Jimenez SA: Impotence in progressively systemic sclerosis. Ann Intern Med 1981, 95:150-153.

3. Nowlin NS, Brick JE, Weaver DJ, Wilson DA, Judd HL, Lu JK, Carlson HE: Impotence in scleroderma. Ann Intern Med 1986, 104:794-798.

4. Hong P, Pope JE, Ouimet JM, Rullan E, Seibold JR: Erectile dysfunction associated with scleroderma: a case-control study of men with scleroderma and rheumatoid arthritis. J Rheumatol 2004, 31:508-513.

5. Lally EV, Jimenez SA: Erectile failure in systemic sclerosis. N Engl I Med 1990, 322:1398-1399.

6. Aversa A, Proietti M, Bruzziches R, Salsano F, Spera G: The penile vasculature in systemic sclerosis: a duplex ultrasound study. I Sex Med 2006, 3:554-558.

7. Nehra A, Hall SJ, Basile G, Bertero EB, Moreland R, Toselli P, de las MA, Goldstein I: Systemic sclerosis and impotence: a clinicopathological correlation. J Urol 1995, 153:1140-1146.

8. Walker $\cup A$, Tyndall $A$, Ruszat R: Erectile dysfunction in systemic sclerosis. Ann Rheum Dis 2009, 68:1083-1085.

9. Walker UA, Tyndall A, Czirjak L, Denton C, Farge-Bancel D, Kowal-Bielecka O, Muller-Ladner U, Bocelli-Tyndall C, Matucci-Cerinic M: Clinical risk assessment of organ manifestations in systemic sclerosis: a report from the EULAR Scleroderma Trials And Research group database. Ann Rheum Dis 2007, 66:754-763.

10. Rosen RC, Cappelleri JC, Smith MD, Lipsky J, Pena BM: Development and evaluation of an abridged, 5-item version of the International Index of Erectile Function (IIEF-5) as a diagnostic tool for erectile dysfunction. Int J Impot Res 1999, 11:319-326.

11. Ponholzer A, Temml C, Mock K, Marszalek M, Obermayr R, Madersbacher S: Prevalence and risk factors for erectile dysfunction in 2869 men using a validated questionnaire. Eur Urol 2005, 47:80-85.

12. McVary KT: Clinical practice. Erectile dysfunction. N Engl J Med 2007, 357:2472-2481.

13. Valentini G, Bencivelli W, Bombardieri S, D'Angelo S, Della RA, Silman AJ, Black CM, Czirjak L, Nielsen H, Vlachoyiannopoulos PG: European Scleroderma Study Group to define disease activity criteria for systemic sclerosis. III. Assessment of the construct validity of the preliminary activity criteria. Ann Rheum Dis 2003, 62:901-903.

14. Feldman HA, Goldstein I, Hatzichristou DG, Krane RJ, McKinlay JB: Impotence and its medical and psychosocial correlates: results of the Massachusetts Male Aging Study. J Urol 1994, 151:54-61.

15. Junuzovic D, Hasanbegovic M, Masic I: Risk factors for erectile dysfunction in patients with newly diagnosed diabetes mellitus. Med Arh 2010, 64:345-347.

16. Yang G, Pan C, Lu J: Prevalence of erectile dysfunction among Chinese men with type 2 diabetes mellitus. Int I Impot Res 2010, 22:310-317.

17. Bener A, Al-Hamaq AO, Kamran S, Al-Ansari A: Prevalence of erectile dysfunction in male stroke patients, and associated co-morbidities and risk factors. Int Urol Nephrol 2008, 40:701-708.

18. Erden I, Ozhan H, Ordu S, Yalcin S, Caglar O, Kayikci A: The effect of nondipper pattern of hypertension on erectile dysfunction. Blood Press 2010, 19:249-253.

19. Heruti RJ, Sharabi Y, Arbel Y, Shochat T, Swartzon M, Brenner G, Justo D: The prevalence of erectile dysfunction among hypertensive and prehypertensive men aged 25-40 years. J Sex Med 2007, 4:596-601.

20. Aranda P, Ruilope LM, Calvo C, Luque M, Coca A, Gil de MA: Erectile dysfunction in essential arterial hypertension and effects of sildenafil: results of a Spanish national study. Am J Hypertens 2004, 17:139-145.

21. Thompson IM, Tangen CM, Goodman PJ, Probstfield JL, Moinpour CM, Coltman CA: Erectile dysfunction and subsequent cardiovascular disease. JAMA 2005, 294:2996-3002.

22. Hatzimouratidis K, Amar E, Eardley I, Giuliano F, Hatzichristou D, Montorsi F, Vardi Y, Wespes E: Guidelines on male sexual dysfunction: erectile dysfunction and premature ejaculation. Eur Urol 2010, 57:804-814.

23. Ostojic P, Damjanov N: The impact of depression, microvasculopathy, and fibrosis on development of erectile dysfunction in men with systemic sclerosis. Clin Rheumatol 2007, 26:1671-1674.
24. Aversa A, Greco E, Bruzziches R, Pili M, Rosano G, Spera G: Relationship between chronic tadalafil administration and improvement of endothelial function in men with erectile dysfunction: a pilot study. Int $J$ Impot Res 2007, 19:200-207.

25. Proietti M, Aversa A, Letizia C, Rossi C, Menghi G, Bruzziches R, Merla A, Spera G, Salsano F: Erectile dysfunction in systemic sclerosis: effects of longterm inhibition of phosphodiesterase type- 5 on erectile function and plasma endothelin-1 levels. J Rheumatol 2007, 34:1712-1717.

doi:10.1186/ar3748

Cite this article as: Foocharoen et al:: Erectile dysfunction is frequent in systemic sclerosis and associated with severe disease: a study of the EULAR Scleroderma Trial and Research group. Arthritis Research \& Therapy 2012 14:R37.

\section{Submit your next manuscript to BioMed Central and take full advantage of:}

- Convenient online submission

- Thorough peer review

- No space constraints or color figure charges

- Immediate publication on acceptance

- Inclusion in PubMed, CAS, Scopus and Google Scholar

- Research which is freely available for redistribution

Submit your manuscript at www.biomedcentral.com/submit
C Biomed Central 